\title{
Experimental Comparison of Heat Transfer by Natural Convection from Plain Vertical Plate and Vertical Plate with Inline Dimples
}

\author{
Prof. S A Wani ${ }^{1 *}$, Prof. S B Khandagale ${ }^{2}$, Vikas Kamalekar ${ }^{3}$, Swapnil Girhe ${ }^{4}$, Gajanan Patil ${ }^{5}$ \\ ${ }^{1,2}$ Assistant Professor, Department of Mechanical Engineering, PadmabhooshanVasantraodadaPatil Institute \\ of Technology, Budhgaon (Sangli), India \\ ${ }^{3,4,5}$ U.G. Students, Department of Mechanical Engineering, Padmabhooshan VasantraodadaPatil Institute of \\ Technology, Budhgaon (Sangli), India
}

*Corresponding Author: Prof. S. A. Wani, Assistant Professor, Department of Mechanical Engineering,
PadmabhooshanVasantraodadaPatil Institute of Technology, Budhgaon (Sangli), India

\begin{abstract}
This paper reveals the experimentation of vertical aluminium plate on which dimples are created and arranged in the form of inline arrangement. The performance parameters of heat transfer like Nusselt number andaverage heat transfer coefficient are determined and compared. The inline dimple plates are tested for various heater inputs like 10W, 20W, 30W, 40W \& 50W. Form the results, it is concluded that the inline dimple plate with 24 dimples is the best arrangement.
\end{abstract}

\section{INTRODUCTION}

The Heat Transfer deals with the study of different ways (modes) of flow of energy and estimation of rate of such energy in transit. In a broad sense, there are three modes ofheat transfer namely Conduction, Radiation and Convection. Heat flows through a substance is Conduction, Heat flows between two surfaces are Radiation and Heat flows between surface and surrounding fluid is Convection. In this report, we are dealing with the Convective type of Heat Transfer. Convection is the mode of energy transfer between a solid surface and the adjacent liquid or gas that is in motion. Types of Convection process are as follows:

\section{Forced Convection}

\section{Natural Convection}

Natural convection is a mechanism, or type of heat transport, in which the fluid motion is not generated by any external source (like a pump, fan, suction device, etc.) but only by density differences in the fluid occurring due to temperature gradients. In natural convection, fluid surrounding a heat source receives heat, becomes less dense and rises. The surrounding, cooler fluid then moves to replace it. This cooler fluid is then heated and the process continues forming convection current; this process transfer's heat energy from the bottom of the convection cell to top. The driving force for natural convection is buoyancy, a result of differences in fluid density. Because of this, the presence of a proper acceleration such as arises from resistance to gra vity, Oran equivalent force (arising from acceleration, centrifugal force or Coriolis effect), is essential for natural convection. For example, natural convection essentially does not operate in free - fall(inertial) environments, such as that of the orbiting International Space Station, where other heat transfer mechanisms are required to prevent electronic components from overheating.

\section{LITERATURE REVIEW}

Kuethe et al. [1] was the first suggest the use of dimple surface for heat transfer Enhancement. Surface dimples are expected to promote turbulent mixing in the flow and Enhance the heat transfer, as they behave as a vortex generator.

M. A. Dafe daret. al. [2] studied experimentally the heat transfer augmentation through various geometries of dimpled surfaces in longitudinal and lateral directions. In his paper horizontal 
rectangular plates of copper and aluminum with different dimpled geometries (like square, circular and triangular) for in-line arrangements were studied in natural convection with steady laminar external flow condition. The various parameters considered for study are Nusselt number, heat transfer coefficient and heat transfer rate for a constant Prandtl number (0.7) and Grash of number(104-107).It has been found that the heat transfer coefficient and heat transfer rate increases for various dimpled surfaces as compared to plane surface. It has been also found that the heat transfer coefficient and heat transfer rate increases along longitudinal direction as compared to lateral direction. And it is seen that heat transfer rate is maximum for triangular shape dimple when the apex of triangle is faced towards inlet of air flow finally it is concluded that heat transfer enhancement takes place along the dimpled surface.

Iftikarahamad H. Patel et. al. [3] presented the computational investigation of convective heat transfer in turbulised flow past a dimpled surface. A parametric study is performed with k- $\varepsilon$ turbulence model to determine the effects of Reynolds number, dimple depth and Nussle number on heat transfer enhancement. In this paper we have computed heat transfer coefficients in a channel with one side dimpled surface. The sphere type dimple geometry was considered with diameter (D) $10 \mathrm{~mm}$ and the depth $(\delta) 4 \mathrm{~mm}$, to obtain $\delta / \mathrm{D}$ ratio as 0.4 and it was increased later to $5 \mathrm{~mm}$ to increase $\delta / \mathrm{D}$ ratio to 0.5 . The Reynolds Number based on the channel hydraulic diameter was varied from 200000 to 360000.Theresults showed that more heat transfer was occurred downstream of the dimples due to flow Reattachment. Due to the flow recirculation on the upstream side in the dimple, the heat transfer coefficient was very low. As the Reynolds number increased, the overall heat transfer coefficient was also increased.

Fahe em Ak tharet. al. [4] experimental investigated the natural convection heat transfer over circular dimpled surfaces is carried out. The various heat transfer parameters considered for study are Nussle number, heat transfer coefficient and heat transfer rate. From the obtained results, it can be concluded that large amount of heat transfer enhancement does takes place for the dimpled surfaces.

Saurabh R Verma et.al [5] studied Heat Transfer enhancement using dimples are based on the principle of scrubbing action of cooling fluid taking place inside the dimple and phenomenon of intensifying the delay of flow separation over the surface. Spherical indentations or dimples have shown good heat transfer characteristics when used as surface roughness. The technology using dimples recently attracted interest due to the substantial heat transfer augmentations it induces, with pressure drop penalties smaller than with other types of heat augmentation. From all the research work studied the researchers have used various dimple shaped geometries such as triangular, ellipsoidal, circular, square out of which ellipsoidal shape gives better results due to prior vortex formation then other shapes.

Amjad Khan et. al. [6] studied the fluid flow and heat transfer characteristics of spherical dimples at different angle of orientation from the centre with apex facing the inlet were investigated. The experiment was carried out for laminar Natural convection conditions with air as a working fluid. The overall Nussle numbers and heat transfer coefficient at different orientation angle of dimples were obtained. From the obtained results, it was observed that the Nussle numbers and heat transfer coefficient increases with decrease in the orientation angle of dimples.

Mahmood et al. [7] studied the flow and heat transfer characteristics over staggered arrays of dimples with $\delta / D=0.2$. For the globally average Nussle number, there were small changes with Reynolds number. He studied the effect of dimpled protrusions (bumps) on the opposite wall of the dimpled surface.

Ligrani et al.[8] experimentally showed the influence of dimple aspect ratio, temperature ratio, Reynolds number and flow structures in a dimpled channel at $\mathrm{Re}=600$ to11,000 and air inlet stagnation temperature ratio of 0.78 to 0.94 with $\mathrm{H} / \mathrm{D}=0.20,0.25,0.5,1.00$. The results indicated that the vortex pairs which are periodically shed from the dimples become stronger and local Nussle number increase as channel height decreases. As the temperature ratio Toi/Tw decreases, the local Nussle number also increased. Burgess et al.[9] experimentally analyses the effect of dimple depth on the surface within a channel with the ratio of dimple depth to dimple printed diameter, equal to $\delta / D$, $0.1,0.2$, and 0.3 . The data showed that the local Nussle number increased as the dimple depth increased due to an increased strength and intensity of vortices and three dimensional (3D) turbulent productions. 
S. D. Hwang et al. [10] in present study, heat transfer and thermal performance of a periodically dimple protrusion patterned surface have been investigated to enhance energy efficiency in compact heat exchangers. The local heat transfer coefficients on the dimple/protrusion walls are derived using a transient TLC (Thermo chromic Liquid Crystal) technique at low Reynolds number. The periodically patterned surface is applied to the bottom wall only or both the bottom and top walls in the test duct. On the single-side patterned walls, various secondary flows generated from the dimple/protrusion coexist. The vortices induced from the upstream affect strongly on the downstream pattern. For the double-side patterned wall case, vortex interaction affected by the opposite wall enhances highly the heat transfer. The heat transfer augmentation is higher in the lower Reynolds number due to the effective vortex interactions. Therefore, the performance factor considering both heat transfer enhancement and pressure loss increases with decreasing the Reynolds number.

\section{EXPERIMENTAL WORK}

From the literature survey, it is found that very few investigators have worked on this type of arrangements. Hence, it is decided to carry out an experimental work to find the enhancement in heat transfer by creating dimples on the surface plate which will be arranged in vertical form and hanged inside an enclosure. The main aim is to find the best possible arrangement of dimples on the vertical plate which will give maximum possible performance.

In order to ascertain the characteristics of dimpled fins, the various arrangements will be carried on the vertical base plate. Therefore, while staggering also, the heat transfer characteristics can be found out and then these readings can be compared for finding the best possible arrangement. The experimental work is carried out by considering Plain Vertical Plate, Vertical Plate with inline circular dimples of diameter $6 \mathrm{~mm}$ (64 Dimples).

\subsection{Vertical Base Plate}

The base plate shown in Fig. 3.1 is used for experimentation work is made up of aluminum and of dimension $150 \mathrm{~mm}$ X $150 \mathrm{~mm}$.

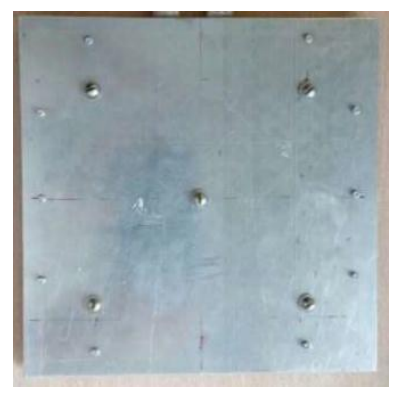

Fig3.1

\subsection{Vertical Plate with Inline Circular Dimples of Diameter 6mm (64 Dimples)}

A vertical plate with inline circular dimples of diameter $6 \mathrm{~mm}$. The small dimples are equally spaced and are arranged in inline manner.

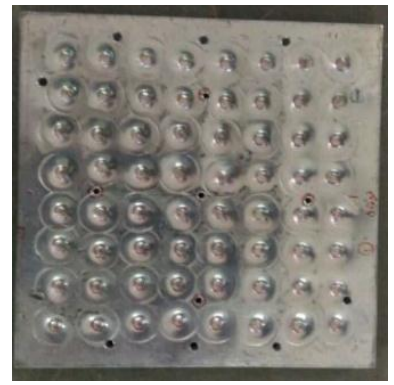

Fig3.2

\subsection{Mica Heater Plate}

The Mica heater plate is used to heat the surface plate. The dimensions of the heater plate are same as the dimensions of the surface vertical plate. The heater plate will be attached to the surface plate with the help of screws. The Fig. 3.4 shows the heater plate with input connections. 


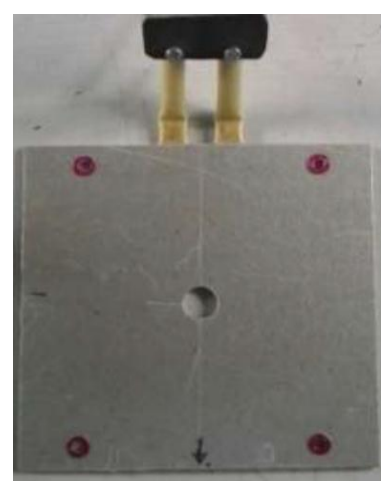

Fig. 3.3

The experimental work conducted is given in the following procedure:

1. Initially, the enclosure was opened from two sides. This is in order to hook the test plate to the enclosure in such a way that heat from heater flows upwards from downward side. After that, the sides of the enclosure ware closed by acrylic sheets.

2. The connections of the thermocouples were made at required positions.

3. The remaining electrical connections were checked i.e. connections of heater and power system etc. and made proper earthling.

4. After checking all the connections, the switch of temperature indicators and dimmer stat is turned ON.

5. The temperatures at different points were read by the digital temperature indicator and were recorded at a time when steady state was reached.

6. After that, by varying dimmer we took another set of readings.

7. The above procedure is repeated again for next set of readings and arrangements.

4. RES ULTS AND DIS CUSSION

The observation tables for various arrangements are mentioned below:

Table4.1. Observation Table for Plain Vertical Plate with Temperature Difference Area $-0.045 \mathrm{~m}^{2}$

\begin{tabular}{|c|l|l|l|l|l|l|l|l|l|}
\hline \multirow{2}{*}{$\begin{array}{c}\text { Heater Input } \\
\text { Q (W) }\end{array}$} & \multicolumn{5}{|c|}{ Plate Temperatures ${ }^{\circ} \mathrm{C}$} & Temp ${ }^{\circ} \mathrm{C}$ & $\mathrm{Ts}^{\circ} \mathrm{C}$ & $\Delta \mathrm{T}^{\circ} \mathrm{C}$ \\
\cline { 2 - 9 } & $\mathrm{T} 1$ & $\mathrm{~T} 2$ & $\mathrm{~T} 3$ & $\mathrm{~T} 4$ & $\mathrm{~T} 5$ & $\mathrm{~T} 6$ & & & \\
\hline 10 & 52.4 & 52.6 & 52.6 & 53.7 & 51.9 & 50.5 & 29.6 & 52.28 & 22.68 \\
\hline 20 & 71.1 & 69.5 & 71.5 & 70.2 & 69.5 & 70.9 & 29.6 & 70.45 & 40.85 \\
\hline 30 & 88.6 & 87.6 & 88.2 & 89.4 & 88.3 & 89.9 & 29.6 & 88.67 & 59.07 \\
\hline 40 & 105.2 & 108.3 & 103.6 & 107.2 & 106.9 & 110.5 & 29.6 & 106.95 & 77.35 \\
\hline 50 & 123.7 & 127.5 & 121.3 & 123.1 & 122.5 & 124.2 & 30.0 & 123.72 & 93.72 \\
\hline
\end{tabular}

Table4.2. Observation Table for Vertical Plate with Inline Circular Dimples of Diameter 6 mm (64 Dimples) with Temperature Difference Area - $0.0486 \mathrm{~m}^{2}$

\begin{tabular}{|c|c|c|c|c|c|c|c|c|c|}
\hline \multirow{2}{*}{$\begin{array}{c}\text { Heater Input } \\
\mathrm{Q}(\mathrm{W})\end{array}$} & \multicolumn{6}{|c|}{ Plate Temperatures ${ }^{\circ} \mathrm{C}$} & \multirow[t]{2}{*}{ Temp ${ }^{\circ} \mathrm{C}$} & \multirow[t]{2}{*}{ Ts ${ }^{\circ} \mathrm{C}$} & \multirow[t]{2}{*}{$\Delta \mathrm{T}^{\circ} \mathrm{C}$} \\
\hline & $\mathrm{T} 1$ & $\mathrm{~T} 2$ & T3 & $\mathrm{T} 4$ & $\mathrm{~T} 5$ & T6 & & & \\
\hline 10 & 48.9 & 49.2 & 48.3 & 47.9 & 48.2 & 47.7 & 28.9 & 48.37 & 19.47 \\
\hline 20 & 67.1 & 68.0 & 65.7 & 65.2 & 65.9 & 64.8 & 29.2 & 66.12 & 36.92 \\
\hline 30 & 84.2 & 85.6 & 81.9 & 81.5 & 82.3 & 80.7 & 29.6 & 82.70 & 53.10 \\
\hline 40 & 101.4 & 103.0 & 98.2 & 97.5 & 98.5 & 96.6 & 29.9 & 99.20 & 69.30 \\
\hline 50 & 118.2 & 120.3 & 114.4 & 113.3 & 114.4 & 111.9 & 29.9 & 115.42 & 85.52 \\
\hline
\end{tabular}

From above observation tables it is seen that, the temperature difference for Plain Vertical Plate is in the range of $22.68^{\circ} \mathrm{C}$ to $93.72^{\circ} \mathrm{C}$. For Vertical Plate with inline circular dimples of diameter $6 \mathrm{~mm}$ with 64 Dimples, it is in the range of $19.47^{\circ} \mathrm{C}$ to $85.52^{\circ} \mathrm{C}$.

The various graphs are plotted to show the different trends and the variation of heat transfer parameters with the change in heater input as shown below. 
Experimental Comparis on of Heat Transfer by Natural Convection from Plain Vertical Plate and Vertical Plate with Inline Dimples
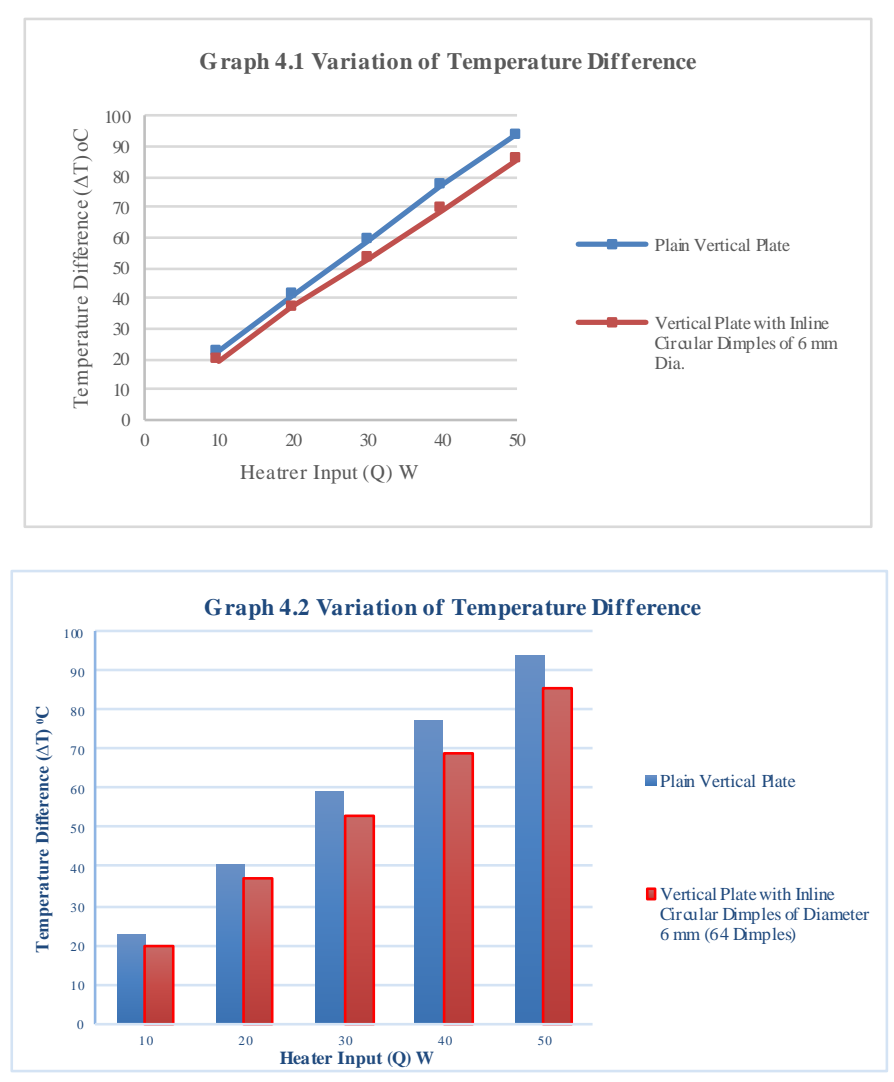

Table4.3. Result Table for Average heat transfer coefficient for Plain Vertical Plate

\begin{tabular}{|c|c|c|c|c|c|c|}
\hline $\begin{array}{c}\text { Heater } \\
\text { Input } \mathrm{Q}(\mathrm{W})\end{array}$ & $\begin{array}{c}\text { Average } \\
\text { Surface Temp. } \\
\mathrm{T}_{\mathrm{s}}\left({ }^{\circ} \mathrm{C}\right)\end{array}$ & $\begin{array}{c}\text { Enclosure } \\
\text { Temperature } \\
\mathrm{T}_{\text {amb. }}\left({ }^{\circ} \mathrm{C}\right)\end{array}$ & $\begin{array}{c}\text { Temperature } \\
\text { Difference } \\
\Delta \mathrm{T}\left({ }^{\circ} \mathrm{C}\right)\end{array}$ & $\begin{array}{c}\text { Qrad. } \\
(\mathrm{W})\end{array}$ & $\begin{array}{c}\text { QConvection } \\
(\mathrm{W})\end{array}$ & $\begin{array}{c}\text { Average Heat } \\
\text { Transfer Coeffient } \\
\mathrm{h}\left(\mathrm{W} / \mathrm{m}^{2} \mathrm{~K}\right)\end{array}$ \\
\hline 10 & 52.28 & 29.6 & 22.68 & 0.77 & 9.23 & 9.04 \\
\hline 20 & 70.45 & 29.6 & 40.85 & 1.52 & 18.48 & 10.05 \\
\hline 30 & 88.67 & 29.6 & 59.07 & 2.40 & 27.60 & 10.38 \\
\hline 40 & 106.95 & 29.6 & 77.35 & 3.43 & 36.57 & 10.51 \\
\hline 50 & 123.72 & 30.0 & 93.72 & 4.50 & 45.50 & 10.79 \\
\hline
\end{tabular}

Table4.4. Result Table for Average heat transfer coefficient for Vertical Plate with inline circular dimples of diameter 6 mm (64 Dimples)

\begin{tabular}{|c|c|c|c|c|c|c|}
\hline $\begin{array}{c}\text { Heater } \\
\text { Input } \\
\mathrm{Q}(\mathrm{W})\end{array}$ & $\begin{array}{c}\text { Average } \\
\text { Surface Temp. } \\
\mathrm{T}_{\mathrm{s}}\left({ }^{\circ} \mathrm{C}\right)\end{array}$ & $\begin{array}{c}\text { Enclosure } \\
\text { Temperature } \\
\mathrm{T}_{\text {amb. }}\left({ }^{\circ} \mathrm{C}\right)\end{array}$ & $\begin{array}{c}\text { Temperature } \\
\text { Difference } \\
\Delta \mathrm{T}\left({ }^{\circ} \mathrm{C}\right)\end{array}$ & $\begin{array}{c}\text { Qrad. } \\
(\mathrm{W})\end{array}$ & $\begin{array}{c}\text { QConvection } \\
(\mathrm{W})\end{array}$ & $\begin{array}{c}\text { Average Heat } \\
\text { Transfer } \\
\text { Coeffient } \\
\mathrm{h}\left(\mathrm{W} / \mathrm{m}^{2} \mathrm{~K}\right)\end{array}$ \\
\hline 10 & 48.37 & 28.9 & 19.47 & 0.70 & 9.30 & 9.83 \\
\hline 20 & 66.12 & 29.2 & 36.92 & 1.45 & 18.55 & 10.34 \\
\hline 30 & 82.70 & 29.6 & 53.10 & 2.26 & 27.74 & 10.75 \\
\hline 40 & 99.20 & 29.9 & 69.30 & 3.19 & 36.81 & 10.93 \\
\hline 50 & 115.42 & 29.9 & 85.52 & 4.25 & 45.75 & 11.01 \\
\hline
\end{tabular}


Experimental Comparis on of Heat Transfer by Natural Convection from Plain Vertical Plate and Vertical Plate with Inline Dimples

From above experimental observations, various parameters such as Heat loss by Radiation, Heat transfer by convection, average heat transfer coefficient, Nussle number, Prandtl number, Grashof number and Rayleigh number are calculated. The various fluid properties like Density, Dynamic Viscosity, Kinematic Viscosity, Specific Heat and Thermal Conductivity are calculated at mean film temperature and are taken from standard tables for dry air.

Table4.5. Result Table for variation in Nusselt Number, Prandtl Number, Grashof Number and Rayleigh number for Plain Vertical Plate

\begin{tabular}{|c|c|c|c|c|c|c|c|}
\hline $\begin{array}{c}\text { Heater } \\
\text { Input Q } \\
(\mathrm{W})\end{array}$ & $\begin{array}{c}\mathrm{T}_{\mathrm{amb}} \\
\left({ }^{\circ} \mathrm{C}\right)\end{array}$ & $\begin{array}{c}\text { Average } \\
\text { SurfaceTemp. } \\
\mathrm{T}_{\mathrm{s}}\left({ }^{\circ} \mathrm{C}\right)\end{array}$ & $\begin{array}{c}\text { Mean } \\
\text { FilmTemp. } \\
\mathrm{T}_{\mathrm{mf}}\left({ }^{\circ} \mathrm{C}\right)\end{array}$ & $\begin{array}{c}\text { Nussle } \\
\text { No. }\end{array}$ & Prandtl No. & Grashof No. & Rayleigh No. \\
\hline 10 & 29.6 & 52.28 & 40.94 & 50.50 & 0.713 & 8596160 & 6125771 \\
\hline 20 & 29.6 & 70.45 & 50.03 & 55.04 & 0.711 & 13834070 & 9841261 \\
\hline 30 & 29.6 & 88.67 & 59.13 & 55.77 & 0.710 & 17939082 & 12741369 \\
\hline 40 & 29.6 & 106.95 & 68.28 & 55.21 & 0.709 & 20854979 & 14788325 \\
\hline 50 & 30.0 & 123.72 & 76.86 & 55.76 & 0.708 & 22971348 & 16267867 \\
\hline
\end{tabular}

Table4.6. Result Table for variation in Nusselt Number, Prandtl Number, Grashof Number and Rayleigh number for Vertical Plate with inline circular dimples of diameter $6 \mathrm{~mm}$ ( 64 Dimples)

\begin{tabular}{|c|c|c|c|c|c|c|c|}
\hline $\begin{array}{c}\text { Heater } \\
\text { Input } \\
\mathrm{Q}(\mathrm{W})\end{array}$ & $\begin{array}{c}\mathrm{T}_{\mathrm{amb}} \\
\left({ }^{\circ} \mathrm{C}\right)\end{array}$ & $\begin{array}{c}\text { Average } \\
\text { SurfaceTemp. } \\
\mathrm{T}_{\mathrm{s}}\left({ }^{\circ} \mathrm{C}\right)\end{array}$ & $\begin{array}{c}\text { Mean } \\
\text { FilmTemp. } \\
\mathrm{T}_{\mathrm{mf}}\left({ }^{\circ} \mathrm{C}\right)\end{array}$ & Nusselt No. & Prandtl No. & Grashof No. & RayleighNo. \\
\hline 10 & 28.9 & 48.37 & 38.63 & 54.67 & 0.712 & 7283483 & 5187692 \\
\hline 20 & 29.2 & 66.12 & 47.66 & 56.14 & 0.711 & 12140716 & 8630734 \\
\hline 30 & 29.6 & 82.70 & 56.15 & 57.10 & 0.710 & 15522284 & 11015489 \\
\hline 40 & 29.9 & 99.20 & 64.55 & 56.85 & 0.709 & 18086790 & 12816243 \\
\hline 50 & 29.9 & 115.42 & 72.66 & 56.15 & 0.699 & 20064522 & 14028376 \\
\hline
\end{tabular}

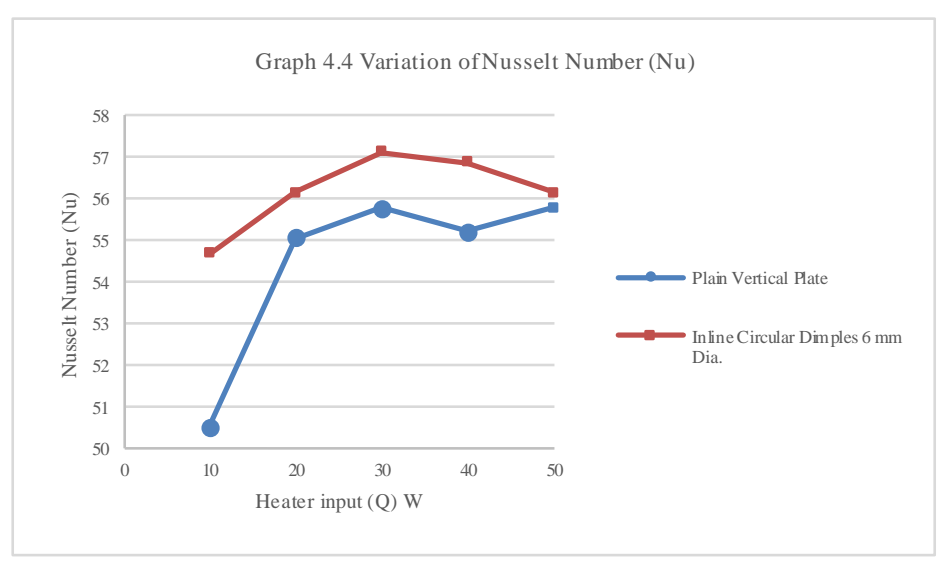

\section{CONCLUSiON}

The present project work is concerned with Experimental Investigation of Natural Convection heat transfer in inline Dimpled Plates. Normally, Rectangular Vertical fins are used in heat sink applications. In the present work, a dimpled plate is used to compare and examine whether it improves the heat transfer performance or not. The dimpled Fins are constructed on the square plate. These dimpled fins are used to enhance the heat transfer under natural convection conditions.

Other Notable Conclusions:

1. In case of Vertical Plate with Inline Circular Dimples, the average heat transfer coefficient is in the range of $\quad 9.83 \mathrm{~W} / \mathrm{m}^{2} \mathrm{~K}$ to $11.01 \mathrm{~W} / \mathrm{m}^{2} \mathrm{~K}$ which is the highest value of average heat transfer coefficient for any other arrangement. This concludes that Vertical Plate with Inline Circular dimples give better performance than Plain Vertical Plate.

2. As the heater input increases from $10 \mathrm{~W}$ to $50 \mathrm{~W}$, the temperature difference also increases, and it is observed that for Vertical Plate with Inline Circular dimples, the temperature difference is in the range of $19.47^{\circ} \mathrm{C}$ to $85.52{ }^{\circ} \mathrm{C}$, which is the lowest as compared to other arrangements. This means that this arrangement gives the better performance. 
3. Nussle number value for Vertical Plate with Inline Circular dimples arrangement is in the range 54.67 to 56.15 , which is the highest as compared to other arrangements.

\section{REFERENCES}

[1] Kuethe A. M.,.Boundary Layer Control of Flow Separation and Heat Exchange, U.S. Patent No. 3,578,264, 1971.

[2] M.A.Dafedar, Mujtabalayeeq I, MohemmedTaherM, MohammadIdressurfShahid I Heat Transfer Enhancement Through Different Circular Diametrical Dimple Surface Under Forced Convection -An Experimental Approach, IJRET: International Journal of Research in Engineering and Technology eISSN: 23191163 | pISSN: 2321-7308, Volume: 02 Is sue: 07 |Jul-2013

[3] Iftikarahamad H. Patel, Dr. Sachin L. Borse, Experimental Investigation Of Heat Transfer Enhancement Over The Dimpled Surface, International Journal of Engineering Science and Technology (IJEST), ISSN : 0975-5462 Vol. 4 No.08 August 2012

[4] Faheem Akthar, Abdul Razak R Kaladgi and Mohammed Same A Dafedar, Heat Transfer Enhancement Using Dimple Surfaces Under Natural Convection-An Experimental Study ,Int. J. Mech. Eng. \& Rob. Res. 2015, ISSN 2278 - 0149 Vol. 4, No. 1, January 2015

[5] Scarab R Verma P. M. Khanwalkar, V. N. Kapatkar, A Review on Heat Transfer Augmentation for Various Dimpled Geometries, International Journal on Theoretical and Applied Research in Mechanical Engineering (IJTARME), ISSN: 2319-3182, Volume -4,Issue-1, 2015

[6] Amjad Khan, Mohammed Zakir Bellary, Mohammad Ziaullah, Abdul RazakKaladgi, An Experimental Study on Heat Transfer Enhancement of Flat Plates Using Dimples, American Journal of Electrical Power and Energy Systems, ISSN: 2326-9200, May 28, 2015.

[7] G.I. Mahmood, M.L. Hill, D.L. Nelson, P.M. Ligrani, H.K. Moon and B. Glezer, Local heat transfer and flow structure on and above a dimpled surface in a channel, J. Turbomachinery 123 (2001) 115-123.

[8] G.I. Mahmood and P.M. Ligrani, Heat Transfer in a dimpled channel: combined influences of aspect ratio, temperature ratio, Reynolds number, and flow structure, Int. J. heat Mass Transfer 45 (2002) 2011-2020.

[9] N.K. Burgess and P.M. Ligrani, Effects of dimple depth on channel nusselt numbers and friction factors, J. Heat Transfer 127 (8) (2005) 839-847.

[10] S. D. Hwang, H. G. Kwon, H. H. Cho, -Local heat transfer and thermal performance on periodically dimple protrusion patterned walls for compact heat exchangers, $\|$ Energy, 2010, vol. 35, p p. 5357-5364

[11] Moon, H.K., O Connell, T., and Glezer, B."Channel Height Effect on Heat Transfer and Friction in a Dimpled Passage" J of Eng. For Gas Turbines and Power, Vol.122, pp.307-313,2000.

[12] Sandeep S. Kore \& Narayan K.Sane, .International Journal of Engineering Science and Technology (IJEST), Vol. 3 , pp 56 - 58, August 2011

Citation: S A Wani et.al. (2018)" Experimental Comparison of Heat Transfer by Natural Convection from Plain Vertical Plate and Vertical Plate with Inline Dimples", International Journal of Modern Studiesin Mechanical Engineering, 4(1), pp.29-35. DOI: http://dx.doi. org/10.20431/2454-9711.0401005

Copyright: (C) 2018 S A Wani, This is an open-access article distributed under the terms of the Creative Commons Attribution License, which permits unrestricted use, distribution, and reproduction in any medium, provided the original author and source are credited. 